\title{
Comparative Antibacterial Analysis of the Anthraquinone Compounds Based on the AIM Theory and Molecular Docking Analysis
}

\author{
Yanjiao Qi \\ Northwest Minzu University \\ Mingyang Wang \\ northwest minzu university \\ Bo Zhang \\ northwest minzu university \\ Yue Liu \\ Northwest Minzu University \\ Hong Zhang \\ northwest minzu university \\ Zhongren Ma \\ Northwest Minzu University \\ Nengzhi Jin \\ gansu computing center \\ Huining Lu ( $\nabla$ xbmuswyx@163.com ) \\ Northwest Minzu University
}

\section{Research Article}

Keywords: DFT, molecular electrostatic potential, AIM theory, molecular docking

Posted Date: October 28th, 2021

DOl: https://doi.org/10.21203/rs.3.rs-988003/v1

License: @ (i) This work is licensed under a Creative Commons Attribution 4.0 International License. Read Full License 


\section{Abstract}

Hydroxyanthraquinones and anthraquinone glucoside derivatives are always considered as the active antibacterial components. In the present text, a comprehensive comparison and analysis of these compounds were performed for their structure characteristics and antibacterial effect by applying quantum chemical calculations, atoms in molecules theory and molecular docking procedure. The molecular geometric configuration, electrostatic potential, the frontier orbital energies and topological properties were analyzed. Once glucose ring is introduced into the hydroxyanthraquinone rings, almost all of the positive molecular potentials are distributed among the hydroxyl hydrogen atoms of the glucose rings. The anthraquinone glucoside compounds have generally higher intermolecular binding energies than the corresponding aglycones due to the strong interaction between the glucose rings and the surrounding amino acids. Once glucoside ring is introduced into the emodin, low electron density $\rho(r)$ and positive Laplacian value of the $\mathrm{O}-\mathrm{H}$ bond are the evidences of the highly polarized and covalently decreased bonding interactions. The type of carboxyl, hydroxyl, hydroxylmethyl groups on phenyl ring and the substituent glucose rings are important to the interactions with the topoisomerase type II enzyme DNA gyrase B.

\section{Introduction}

With the widespread use of antibiotics and the emergence of resistant bacteria, there is a need for developing new antibacterial compounds that have new mechanisms of action with activity against bacterial strains. Therefore, the search for new antibacterial agents remains a significant challenge for the future. Natural products are structurally complex and pharmacologically valuable products, the separation, synthesis and the structure-activity relationship attract extensive attention for scientific research. There are three authorised Rhubarbs in Chinese Pharmacopoeia, namely Rheum palmatum L., Rheum tanguticum Maxim. ex Balf and Rheum officinale Bail with the roots and rhizomes generally called official rhubarbs. Rhubarb contains a lot of active compounds, such as anthraquinone, anthrone, buty-rophenone, tannin and some glycoside derivatives, and it also has the functions of purging heat, clearing the intestines, cooling blood, lowering blood sugar, antibacterial, antiviral, anti-tumor and lipid-lowering, etc. (Zhu et al., 2016). The hydroxyanthraquinones are considered as the active antibacterial components, such as aloe-emodin, rhein, emodin and chrysophanol (Wang et al., 2010). In addition, some anthraquinone glucoside derivatives are also attracting more and more attentions due to their good microbicidal activities (Li et al., 2019; Zhang et al., 2021). It was reported that the anthraquinone glucosides were much more potent than their corresponding aglycones. For example, emodin has lower bacterial neuraminidase inhibitory activity than the corresponding glucoside derivative (Uddin et al., 2016). However, there are few comparative researches about the anthraquinone and its glycosides.

DNA gyrase is a member of topoisomerase type II enzyme, which controls the topology of DNA in the time of transcription, replication and recombination processes (Tomašić and Mašič, 2014). DNA gyrase is composed of two A subunits (GyrA) and two B subunits (GyrB), where the GyrA is involved in DNA transit and the GyrB subunit contains an ATP-binding domain (Champoux, 2001). DNA gyrase has proven to be a worthy target for antimicrobial agents (Gellert et al., 1976). A lot of new inhibitors were developed and evaluated against the DNA gyrase B to explore new antibacterial drugs (Durcik et al., 2018; Azam et al., 2015; 
Jogula et al., 2020). Due to the absence of detailed report about the relationship of the structureantibacterial activity for these aglycones and their anthraquinone glucoside derivatives by now, the aim of present review is to give a comprehensive comparison and analysis of these compounds derived from rhubarb by applying standard quantum chemical calculations (Gonçalves et al., 2014), Bader's theory (Bader, 1990) of atoms in molecules (AIM) and molecular docking procedure (Guisasola et al., 2016; Jerome et al., 2016; Singh et al., 2012) selected the DNA gyrase as a target.

\section{Material And Methods}

The molecular structure optimization of the compounds and corresponding energies are calculated by using GAUSSIAN 09W program package (Frisch et al., 2009). The DFT with Becke-3-Yang-Parr (B3LYP) combined with standard basis sets 6-31G $(\mathrm{d}, \mathrm{p})$ was applied. Topology analysis of electron density and the molecular electrostatic potential surfaces on van der Waals ( $\mathrm{vdW}$ ) surface in both forms were performed by using the Multiwfn program (Lu and Chen, 2012). The protein of the template structure DNA gyrase B (PDBID: 4DUH) was downloaded from PDB website (http://www.rcsb.org). In target DNA gyrase B preparation, the missing atoms were identified and repaired. The crystal water $\left(\mathrm{H}_{2} \mathrm{O}\right)$ molecules and other ligands were deleted. The polar hydrogen atoms and Gasteiger charge were added. The protein molecule was also assigned AD4 type. The ligand was docked into the catalytic pocket of the DNA gyrase B based on the AutoDock 4.2 program (Morris et al., 2009). Genetic algorithm with default settings was set in the search parameter, and the number of runs was set at 100 . The configuration file with binding site information was generated with grid coordinates $3.024,2.008$ and 36.865 for $x-, y$ - and z-axis respectively. The docking grid box was set at $60 \cdot 60 \cdot 60$ points with a spacing value of $0.375 \AA$. Topological analysis has been performed by using AIMALL package (Parameswari and Kumaradhas, 2013), and the corresponding wave functions were also generated in order to gain further insights into the bonding characters.

\section{Results And Disscussion}

\subsection{Molecular geometry}

These anthraquinone compounds were subjected to geometry optimization in the ground state. The optimized molecular structure of the anthraquinone compounds with atom numbering scheme adopted in the present study is presented in Fig. 1. On compared with the optimized phase, geometric conformations of these compounds changed obviously after interacting with the DNA gyrase $B$ at the active site. There are obvious changes about the bond angles and dihedral angles rather than the bond lengths, which suggested strong inter-molecular interactions. The corresponding structural parameters (bond length and dihedral angle) are listed in Supplementary Table S1. Compared with the optimized structure, it can be seen from the Table S1 that there is almost no change in the length of each bond of compounds at the active site. The glucose ring that binds to the aromatic ring ketone is obviously bent at the active site, ascribing to the more serious intermolecular interaction with surrounding amino acids (Wang et al., 2010). In general, almost all of the anthraquinone skeleton planes are stable, whereas the angles between the glucose groups and the phenyl ring are more or less changed (Fig. 1). This can be concluded that the interactions of these 
anthraquinone compounds might be related with the type and number of substituent groups on the molecular structure, as well as the substituted glucose rings.

\subsection{Molecular docking}

According to the literature (Devipriya and Kumaradhas, 2013; Zhu et al., 2021), the binding modes and binding affinities play important roles in the inhibition of the small molecules to the enzyme. Results indicated that the selected binding affinities for these complexes of molecules-DNA gyrase B are from -7.27 to $-10.24 \mathrm{Kcal} / \mathrm{mol}$. It is worth noting that the bonding energies of the anthraquinones are $-8.50,-8.24,-7.27$, -7.91 and $-7.66 \mathrm{kcal} / \mathrm{mol}$ for molecules M1-M5, respectively. However, the corresponding anthraquinone glucoside compounds have generally higher intermolecular binding energy due to the strong interaction between the glucose ring and the surrounding amino acids Asn46, Arg76, Pro79, Gly101, and Lys103 (-10.24囚-9.47囚-9.74囚-9.31 and $-9.11 \mathrm{kcal} / \mathrm{mol}$ for molecules M6-M10, respectively). This is consisted with the experience result that the anthraquinone glucosides have much more antibacterial effect than their corresponding aglycones (Wang et al., 2010). At the same time, the structure of the glucose ring has also undergone significant changes (Table S1). Among them, the 01 of the glucose ring of the lowest binding energy molecule M6 $(-10.24 \mathrm{Kcal} / \mathrm{mol})$ forms a hydrogen bond with the hydrogen atom HD21 of ASN46 at a length of $2.197 \AA$, and the side hydroxyl group of the glucose ring forms hydrogen bond interactions with LYS103 and ASN46 at length of $2.091 \AA$ and $2.062 \AA$, respectively (Fig. 2f).

Compared with the compound M6, the glucose ring at the active site of M7 rotates clearly clockwise, resulting in a smaller angle with the anthraquinone ring plane. The dihedral angle of C11-C12-018-C26 is changed from $16.23^{\circ}$ at the optimized state to $-116.95^{\circ}$, which can be ascribed to the strong hydrogen bonding and electrostatic interactions with surrounding amino acids Asn46, Ala100, Phe104, Gly117 and Val120 (Fig. 2g). Besides the multiple hydroxyl groups on the anthraquinone skeleton, hydroxyl groups of the glucose ring are also important to the antimicrobial effect, which may be ascribed as the hydrogen bonding interactions at the active site. In fact, the combined anthraquinone chrysophanol 8-0-beta-Dglucoside shows good bioactivity on compared with the free chrysophanol (Li et al., 2007). Therefore, the influence of substituent groups on anti- DNA gyrase B activity might not only be related with the type and number of substituent carboxyl, hydroxyl and hydroxylmethyl on phenyl ring groups, but also the combined glucose rings. Compared with the hydroxyanthraquinones, the interact area of the whole anthraquinone glucosides are larger (the part shown by the purple circle in Fig. $2 \mathrm{k}$ ), between which the hydrophobic interaction plays a very important role. The nearest neighbors and short contact distances $(\AA)$ of anthraquinone compounds with the amino acid residues of DNA gyrase B are shown in Table 1.

\subsection{Molecular electrostatic potential}

Molecular electrostatic potential (MEP) on molecular vdW surface is an important parameter to study the intermolecular interaction (Murray and Politzer, 1998; Murray and Politzer, 2011; Lu and Chen, 2012). Usually, MEP is also related to the electronic density (Vijayalakshmi and Suresh, 2008), thus it is always used to anticipate reactive sites that electrophilic and nucleophilic reagents attack (Selvaraju et al., 2012). In this text, the negative (green) and positive (red) regions are regarded as electrophilic and nucleophilic reactivity regions, respectively (Fig. 5), while the white regions shows zero potential. In general, the 
electrostatic potential distribution of anthraquinone compounds is more uniform than that of the anthraquinone glucosides. The main positive charge is distributed near the hydrogen atom of the hydroxyl group on the side chain of the aromatic ring plane. For the molecule M3, the oxygen atom 018 in the carboxyl group acts as an electron donor to form a hydrogen bonding interaction with the $\mathrm{HH} 11$ of the amino acid Arg136, and thence the region at vicinity of the connected hydrogen atom $\mathrm{H} 28$ remains the highest electrostatic potential value of $66.73 \mathrm{Kcal} / \mathrm{mol}$. Due to the strong interaction between the side chain hydroxyl oxygen atoms (017 and 019) of molecule M1 and the surrounding amino acid Gly77, and the electrostatic interaction between the oxygen atom 015 of the anthraquinone ring and amino acid Arg76, the electrostatic potential has reached the lower value of $-58.25 \mathrm{Kcal} / \mathrm{mol}$ (Fig. 3a).

Once glucose ring is introduced into the hydroxyanthraquinone plane, it was shown that almost all of the positive molecular potentials of anthraquinone glucosides are distributed among the hydroxyl hydrogen atoms of the glucose structures except the molecule M9. These substituent hydroxyl groups on the molecular aromatic ring interact with the amino acids Glu42, Asn46 and Gly 11 by hydrogen bonding and electrostatic interaction, which might lead to imbalance of distribution of electrons (the value of the global surface maximum is $75.40 \mathrm{Kcal} / \mathrm{mol}$, Fig. 3i). In general, due to the presence of the hydroxyl group in the glucose ring, it can interact with surrounding amino acids Lys103, Asn46, Ala100, Phe104 and Val120 by intermolecular hydrogen bonds, electrostatic attraction and Van der Waals forces, resulting in major changes in the molecular structure and the molecular electrostatic potential distribution. In general, the positive molecular potentials at the vicinity of the molecular hydrogen atom are increased obviously when glucose ring is introduced into the hydroxyanthraquinone ring. For example, the global surface maximum of $\mathrm{M} 1$ is $61.35 \mathrm{Kcal} / \mathrm{mol}$ while the value changed to be $70.18 \mathrm{Kcal} / \mathrm{mol}$ for M6, the value of M2 (44.37 $\mathrm{Kcal} / \mathrm{mol})$ increased about $8.19 \mathrm{Kcal} / \mathrm{mol}(52.56 \mathrm{Kcal} / \mathrm{mol})$ for $\mathrm{M} 8$. This indicated that the electronic cloud of the aromatic side chain has shifted while interacting with the bonding site.

\subsection{The molecular orbitals}

The important Frontier Molecular Orbital (FMOs) are highest (HOMO) occupied molecular orbitals and the lowest (LUMO) unoccupied one, which play an important part in the chemical stability of the molecule (Lim et al., 2011). The HOMO represents the ability to donate an electron, while the electron acceptor LUMO represents the ability to accept an electron. The energy gap between HOMO and LUMO also determines the chemical reactivity, optical polarizability and chemical hardness-softness of the molecule (Huang et al., 2017). According to the Koopman's theorem, $E_{\text {HOMO }}$ and $E_{\text {LUMO }}$ values of any chemical type are associated with its ionization energy and electron affinity values, respectively (Plakhutin and Davidson, 2009). In

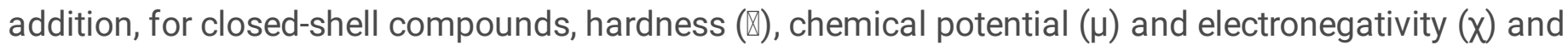
softness are also defined. Recently, a new descriptor electrophilicity index $(\omega)$ has also been defined to quantity the global electrophilic power of the compound (Tandon et al., 2019). Dipole moment $D$ (debye) is also shown in Table 2 . The usefulness of this new reactivity quantity has been recently demonstrated in understanding the toxicity of various pollutants in terms of their reactivity and site selectivity (Abraham et al., 2019).

$\nabla=(I-A) / 2$ 
$\mu=-(1+A) / 2$

$X=(I+A) / 2$

$\omega=\mu^{2} / 2 \rrbracket$

Where, $\mathrm{A}$ and I are the ionization potential and electron affinity of the compounds respectively.

Commonly, the atom occupied by more densities of HOMO should have stronger ability to detach an electron whereas the atom with more occupation of LUMO should have ability to gain an electron. In the present study, the HOMO and LUMO energies are predicted at B3LYP method with 6-31G (d, p) basis sets. It is clear from Fig. 4 that the positive and negative phase is represented in orange and green color respectively. It can be seen from the plots that the region of HOMO and LUMO levels spread over the free anthraquinones (M1-M5). However, the HOMO and the LUMO orbitals are located all over the anthraquinone ring plane of anthraquinone glucosides rather than the glucose ring. This indicated that the atom with more occupation of LUMO should have ability to gain an electron (Mezzina et al., 2021). However, the hydroxyl oxygen atoms in the glucose ring act as electron donors and easily form hydrogen bonding interactions with the surrounding amino acids, resulting in stronger ability to detach electrons. It is interesting for M9 to find that the glucose ring donates electrons, while the anthraquinone ring plane accepts electrons. From the energy levels of HOMO and LUMO orbital for these anthraquinone compounds at the active site (Table 2), it can be seen that the energy gap of HOMO-LUMO is the highest for M9 $(0.148 \mathrm{ev})$, which reflects the chemical stability of the molecule.

Due to the molecular resistance can change or deform the number of electrons, chemical hardness $(\eta)$ is associated with the stability and reactivity of a chemical system (Adejumo et al., 2020). The combined anthraquinone $\mathrm{M} 9$ has the highest $\Delta \mathrm{E}_{\mathrm{gap}}$, which shows a stable molecule and it needs much excitation energy to reach the manifolds of excited states (Huang et al., 2017). As can be seen, the calculations electrophilicity $(\omega)$ performed at anthraquinone glucosides are very close to each other when compared with the anthraquinones. The other important electronic property dipole moment values for the molecules are also given in Table 2. Generally, the combined anthraquinone glucosides have larger dipole moments than that of the free anthraquinones.

\subsection{Topological properties analysis}

In general, the charge concentration/depletion at the BCP (bond critical point) of the chemical bond provides interesting information about the chemical bonds by using the Laplacian of electron density $\nabla^{2} \rho_{b c p}$ (Wang et al., 2016; Prabavathi and Nilufer, 2015). Due to emodin (M1) and its anthraquinone glucoside emodin-8beta- glucosicide (M6) have the lowest binding energies among the structural analogues, we paid attention to the change of their electron densities of the chemical bonds. Based on the Multiwfn program, the $(3,-1)$ type of BCP for all chemical bonds of M1 and M6 were evaluated for both two status. Based on further topological analysis, the electron density $\left(\rho_{\mathrm{bcp}}\right)$ and their Laplacian values $\left(\nabla^{2} \rho_{\mathrm{bcp}}\right)$ are listed in Supplementary Table S2. The $(3,-1)$ type of BCP for all chemical bonds were found by the Multiwfn program suggested the existence of the covalent interactions (Lu and Chen, 2012). It can be seen from 
Supplementary Table S3 that the electron densities of the molecule M6 at active site are very close to the optimized phase.

However, the electron densities of the M1 at active site are higher than that of the other status. The electron densities $\left(\rho_{\mathrm{bcp}}\right)$ of the $\mathrm{C}-\mathrm{C}$ bonds on aromatic ring for these molecules in both forms are ranged from 1.583 to $2.159 \mathrm{e}^{-3}$, implying strong covalent interactions (Luis, 2016). Due to the strong electrostatic interactions between the carbonyl 07 atom and amino acids Asn46, His99, Phe104 and Val118, the electron density of the bond C6-07 remains the highest value. In short, almost all of the electron densities of M1 at the active site are reduced, while the M6 remains constant (Fig. 5). On compared with other chemical bonds, the electron densities of all $\mathrm{O}-\mathrm{H}$ and $\mathrm{C}-\mathrm{O}$ bonds are generally higher while the corresponding Laplacian values are lower except C6-07, which suggests that the charge densities at the BCP are highly concentrated.

On the other hand, low value of electron density and positive character of the Laplacian for M1 are the evidences for the covalently rupture of $\mathrm{C6}-07$ bond. Moreover, a change in the sign of the Laplacian from the positive values $\left(4.952 \mathrm{e}^{-5}\right)$ to a negative character at the active site $\left(-6.037 \mathrm{e} \AA^{-5}\right)$, indicates the depletion of the charge density confirming the $\mathrm{C} 6-07$ bond of $\mathrm{M} 1$ cleavage while interacting with the DNA gyrase $\mathrm{B}$. Once glucoside ring is introduced into the M1 (Fig. 5), low value of electron density $\rho(r)$ and positive data of the Laplacian of the 019-H27 are the evidences of the highly polarized and covalently decreased bonding interaction (Luis, 2016). Actually, most of the Laplacian values of electron densities are reduced at the active site. Among which, the highest electron density values $\left(2.766-2.788 \mathrm{e}^{-3}\right)$ can be found on the carbonyl C-O bonds of the parent ring in both situations. The electronic Laplace values are all negative for $\mathrm{M} 1$ molecule except the positive values of $\mathrm{C} 14-015$ and $\mathrm{C6}-07$ on the anthraquinone ring plane, implying a more concentrated character at the active site. The electron densities of the three hydroxyl groups on the M1 hydroxyanthraquinone plane become more depleted after interacting with the DNA gyrase B, implying strong hydrogen bonding interactions with the surrounding amino acids Gly77, Gly101and Asp25 (Renuga et al., 2015). Most of the covalent bonds of the $M 6$ molecule become more aggregated, which may be related to a more stable structure at the active site. However, positive character of the Laplacian values are the evidences for the covalently rupture of $\mathrm{C14}-015$ and $\mathrm{C6}-07$. This is described to the strong electrostatic interactions with the surrounding polar amino acids Arg136, Glu137, Gly164, Val118, Val97 and His99 etc.

\section{Conclusion}

Rhubarb is a widely used traditional medicine and has been reported to elicit a number of biological effects, such as antibacterial effects. There are a lot of active compounds that were isolated from Rhubarb including some anthraquinone and anthraquinone glucosides. It was concluded from this text that almost all of the anthraquinone skeleton planes are constant when interacting with the target protein DNA gyrase B.

Compared with the multiple hydroxyl groups on the anthraquinone skeleton, hydroxyl groups of the glucose ring are also important to the antimicrobial effect, which may be ascribed as the hydrogen bonding interactions at the active site. In contrast to the average distribution of anthraquinone compounds, MEP analysis indicated that the almost all of the positive molecular potentials of anthraquinone glucosides are distributed among the hydroxyl hydrogen atoms of the glucose structures. In fact, the electron densities of the hydroxyanthraquinone are generally higher than that of the corresponding anthraquinone glucosides. 
The electron densities become more depleted after docking with the DNA gyrase B, especially the hydroxyl groups. Although the anthraquinone glucosides were much more potent antibacterial effects than their corresponding aglycones, the raw Rhubarb is traditionally converted to processed Rhubarb by specialized heating to alleviate its side effects most probably caused by anthraquinones glucosides (Qin et al., 2011). It may be concluded that not only the functional groups carboxyl, hydroxyl and hydroxylmethyl, but also the glucose ring on phenyl ring can improve the antimicrobial activity. The structure-antibacterial effect of the hydroxyanthraquinone and anthraquinone glucosides can provide more references and insights for studying the antibacterial action mechanism of these natural components of Rhubarb.

\section{Declarations}

\section{Acknowledgments}

This work was supported by the Fundamental Research Funds for the Central Universities (31920200075).

\section{Competing interests}

The authors declare they have no competing interests.

\section{Availability of data and material}

The data and material are available.

\section{Authors' contributions}

Qi YJ: Writing. Wang MY: Methodology. Zhang B: Methodology. Liu Y: Methodology. Zhang H: Data curation. Ma ZR: Supervision. Jin NZ: Software. Lu Huining: Writing - review \& editing.

\section{Supplementary material}

The structure parameters, electron densities, Laplacian value of all molecules calculated in both forms are given in Supplementary Tables.

\section{References}

1. Abraham CS, Muthu S, Prasana JC, Armaković S, Armaković SJ, Rizwana B F, Geoffrey B, David R HA (2019) Computational evaluation of the reactivity and pharmaceutical potential of an organic amine: A DFT, molecular dynamics simulations and molecular docking approach. Spectrochim Acta A Mol Biomol Spectrosc 222:117188.

2. Adejumo TT, Tzouras NV, Zorba LP, Radanović D, Pevec A, Grubišić S, Mitić D, Anđelković KK, Vougioukalakis GC, Čobeljić B, Turel I (2020) Synthesis, Characterization, Catalytic Activity, and DFT Calculations of Zn(II) Hydrazone Complexes. Molecules 25(18): 4043.

3. Azam MA, Thathan J, Jubie S (2015) Dual targeting DNA gyrase B (GyrB) and topoisomerse IV (ParE) inhibitors: A review. Bioorg Chem 62:41-63. 
4. Bader RFW (1990) Atoms in Molecules: A Quantum Theory. Oxford University Press: Oxford, U.K.

5. Champoux JJ (2001) DNA topoisomerases: structure, function and mechanism. Annu Rev Biochem 70: 369-413.

6. Devipriya B, Kumaradhas P (2013) Molecular flexibility and the electrostatic moments of curcumin and its derivatives in the active site of p300: a theoretical charge density study. Chem Biol Interact 204: 153156.

7. Durcik M, Tammela P, Barančoková M, Tomašič T, llaš J, Kikelj D, Zidar N (2018) Synthesis and Evaluation of N-Phenylpyrrolamides as DNA Gyrase B Inhibitors. ChemMedChem 13(2): 186-198.

8. Frisch MJ, Trucks GW, Schlegel HB, Scuseria GE, Robb MA, Cheeseman JR, Scalmani G, Barone V, Mennucci B, Petersson GA, Nakatsuji H, Caricato M, Li X, Hratchian HP, Izmaylov AF, Bloino J, Zheng G, Sonnenberg JL, Hada M, Ehara M, Toyota K, Fukuda R, Hasegawa J, Ishida M, Nakajima T, Honda Y, Kitao O, Nakai H, Vreven T, Montgomery JAJr, Peralta JE, Ogliaro F, Bearpark M, Heyd JJ,Brothers E, Kudin KN, Staroverov VN, Kobayashi R, Normand J, Raghavachari K, Rendell A, Burant JC, lyengar SS, Tomasi J, Cossi M, Rega N, Millam JM, Klene M, Knox JE, Cross JB, Bakken V, Adamo C, Jaramillo J, Gomperts R, Stratmann RE, Yazyev O, Austin AJ, Cammi R, Pomelli C, Ochterski JW, Martin RL, Morokuma K, Zakrzewski VG, Voth GA, Salvador P, Dannenberg JJ, Dapprich S, Daniels AD, Farkas Ö, Foresman JB, Ortiz JV, Cioslowski J, Fox DJ. Gaussian 09, Revision E.01 (2009) Gaussian, Inc., Wallingford CT.

9. Gellert M, Mizuuchi K, O'Dea MH, Nash HA (1976) DNA gyrase: an enzyme that introduces superhelical turns into DNA. Proc Natl Acad Sci USA 73(11): 3872-3876.

10. Gonçalves AS, França TCC, Caetano MS, Ramalho TC (2014) Reactivation steps by 2-PAM of tabuninhibited human acetylcholinesterase: reducing the computational cost in hybrid QM/MM methods. J Biomol Struct Dyn 32: 301-307.

11. Guisasola EEB, Gutierrez LJ, Salcedo RE, Garibotto FM, Andujar SA, Enriz RD, Rodriguez AM (2016) Conformational transition of A beta(42) inhibited by a mimetic peptide. A molecular modeling study using QM/MM calculations and QTAIM analysis. Comput Theor Chem 1080: 56-65.

12. Huang Y, Rong CY, Zhang RQ, Liu SB (2017) Evaluating frontier orbital energy and HOMO/LUMO gap with descriptors from density functional reactivity theory. J Mol Model 23 (1): 3.

13. Jerome DR, Guillaume B, Ralf B, Marc L (2016) Molecular docking as a popular tool in drug design, an in silico travel. Adv Appl Bioinform Chem 9: 1-11.

14. Jogula S, Krishna VS, Meda N, Balraju V, Sriram D (2020) Design, synthesis and biological evaluation of novel Pseudomonas aeruginosa DNA gyrase B inhibitors. Bioorg Chem 100:103905.

15. Li X, Liu YJ, Chu SF, Yang SW, Peng Y, Ren SY, Wen BR, Chen NH (2019) Physcion and physcion 8-0- $\beta$ glucopyranoside: A review of their pharmacology, toxicities and pharmacokinetics. Chem Biol Interact 310:108722.

16. Li Z, Li LJ, Sun Y, Li J (2007) Identification of natural compounds with anti-hepatitis B virus activity from Rheum palmatum L. ethanol extract. Chemotherapy 53(5): 320-326.

17. Lim J, Albright TA, Martin BR, Miljanić OŠ (2011) Benzobisoxazole cruciforms: heterocyclic fluorophores with spatially separated frontier molecular orbitals. J Org Chem 76(24): 10207-10219. 
18. Lu T, Chen FW (2012) Quantitative analysis of molecular surface based on improved Marching Tetrahedra algorithm. J Mol Graph Model 38: 314-323.

19. Lu T, Chen FW (2012) Multiwfn: a multifunctional wavefunction analyzer. J Comp Chem 33: 580-592.

20. Luis R Domingo (2016) Molecular Electron Density Theory: A Modern View of Reactivity in Organic Chemistry. Molecules 21(10): 1319.

21. Mezzina Freitas LP, Feliciano GT (2021) Atomic and Electronic Structure of Pilus from Geobacter sulfurreducens through QM/MM Calculations: Evidence for Hole Transfer in Aromatic Residues. J Phys Chem B 125(30): 8305-8312.

22. Morris GM, Huey R, Lindstrom W, Sanner MF, Belew RK, Goodsell DS, Olson AJ (2009) Autodock4 and AutoDockTools4: automated docking with selective receptor flexibility. J Comput Chem 16: 2785-2791.

23. Murray JS, Politzer P (1998) Electrostatic potentials: chemical applications. In: Schleyer PvR (ed) Encyclopedia of computational chemistry. Wiley, West Sussex, pp 912-920.

24. Murray JS, Politzer P (2011) The electrostatic potential: an overview. Wiley Interdiscip Rev 1:153-163.

25. Parameswari AR, Kumaradhas $P$ (2013) Exploring the conformation, charge density distribution and the electrostatic properties of galanthamine molecule in the active site of AChE using DFT and AIM theory. Int J Quant Chem. 113:1200-1208.

26. Plakhutin BN, Davidson ER (2009) Koopmans' theorem in the restricted open-shell Hartree-Fock method. 1. A variational approach. J Phys Chem A 113(45):12386-12395.

27. Prabavathi N, Nilufer A (2015) Quantum chemical calculations on elucidation of molecular structure and spectroscopic insights on 2-amino-4-methoxy-6-methylpyrimidine and 2-amino-5-bromo-6- methyl4-pyrimidinol-a comparative study. Spectrochim Acta A Mol Biomol Spectrosc 136 Pt B: 192.

28. Qin Y, Wang JB, Kong WJ, Zhao YL, Yang HY, Dai CM, Fang F, Zhang L, Li BC, Jin C, Xiao XH (2011) The diarrhoeogenic and antidiarrhoeal bidirectional effects of rhubarb and its potential mechanism. $J$ Ethnopharmacol 133(3):1096-1102.

29. Renuga Parameswari A, Rajalakshmi G, Kumaradhas P (2015) A combined molecular docking and charge density analysis is a new approach for medicinal research to understand drug-receptor interaction: curcumin-AChE model. Chem Biol Interact 225: 21-31.

30. Selvaraju K, Jothi M, Kumaradhas $P$ (2012) Understanding the charge density distribution and the electrostatic properties of hexadecane molecular nanowire under electric field using DFT and AIM theory. Comput Theor Chem 992: 9-17.

31. Singh RN, Baboo V, Rawat P, Kumar A, Verma D (2012) Molecular structure, spectral studies, intra and intermolecular interactions analyses in a novel ethyl 4-[3-(2-chloro-phenyl)-acryloyl] -3,5-dimethyl-1Hpyrrole-2-carboxylate and its dimer: A combined DFT and AIM approach, Spectrochim Acta. A Mol Biomol Spectrosc 94: 288-301. doi: 10.1016/j.saa.2012.03.059.

32. Tandon H, Chakraborty T, Suhag V (2019) A model of atomic compressibility and its application in QSAR domain for toxicological property prediction. J Mol Model 25(10): 303.

33. Tomašić T, Mašič LP (2014) Prospects for developing new antibacterials targeting bacterial type IIA topoisomerases. Curr Top Med Chem 14(1): 130-151. 
34. Uddin Z『Song YH『Curtis-Long MJ『Kim JY₫Yuk HJ, Park KH (2016) Potent bacterial neuraminidase inhibitors, anthraquinone glucosides from Polygonum cuspidatum and their inhibitory mechanism. $J$ Ethnopharmacol 193: 283-292.

35. Vijayalakshmi KP, Suresh CH (2008) Theoretical studies on the carcinogenic activity of diol epoxide derivatives of PAH: proton affinity and aromaticity as decisive descriptors. Org Biomol Chem 6: 43844390.

36. Wang J, Zhao H, Kong W, Jin C, Zhao Y, Qu Y, Xiao X (2010) Microcalorimetric assay on the antimicrobial property of five hydroxyanthraquinone derivatives in rhubarb (Rheum palmatum $L$.) to Bifidobacterium adolescentis. Phytomedicine 17(8-9): 684-689.

37. Wang L, Li T, Shen Y, Song Y (2016) A theoretical study of the electronic structure and charge transport properties of thieno[2,3-b]benzothiophene based derivatives. Phys Chem Chem Phys 18(12): 8401.

38. Zhang YC, Zhu Y, Zuo YP, Tang CF, Zhou F, Cui XM, Wang L (2021) Effects of Rhein-8-O- $\beta$-Dglucopyranoside on the Biofilm Formation of Streptococcus mutans. Curr Microbiol 78(1): 323-328.

39. Zhu TT, Liu X, Wang XL, Gang C, Qin KM, Pei K, Zhu H, Cai H, Niu MJ, Cai BC (2016) Profiling and analysis of multiple compounds in rhubarb decoction after processing by wine steaming using UHPLCQ-TOF-MS coupled with multiple statistical strategies. J Sep Sci 39 (15): 3081-3090.

40. Zhu Y, Alqahtani S, Hu X (2021) Aromatic Rings as Molecular Determinants for the Molecular Recognition of Protein Kinase Inhibitors. Molecules 26(6):1776.

\section{Tables}

Table 1 Nearest neighbors and short contact distances $(\AA)$ of anthraquinone compounds with the amino acid residues of $E$. coli DNA gyrase B. 


\begin{tabular}{|c|c|c|c|c|c|c|c|}
\hline $\begin{array}{l}\text { Molecular... } \\
\text { DNA }\end{array}$ & gyrase & $\begin{array}{l}\text { Molecular... } \\
\text { DNA }\end{array}$ & gyrase & $\begin{array}{l}\text { Molecular... } \\
\text { DNA }\end{array}$ & $\begin{array}{l}\text { gyrase } \\
\mathrm{B}\end{array}$ & $\begin{array}{l}\text { Molecular... } \\
\text { DNA }\end{array}$ & $\begin{array}{l}\text { gyrase } \\
\mathrm{B}\end{array}$ \\
\hline M1 & & M2 & & M3 & & M4 & \\
\hline 017...Gly77/H & 1.950 & $\begin{array}{l}\text { 07... } \\
\text { Gly119/H }\end{array}$ & 1.829 & $\begin{array}{l}\text { O21... } \\
\text { Asn46/HD1 }\end{array}$ & 2.164 & 03...Gly77/H & 1.936 \\
\hline 015...Gly77/H & 2.549 & $\begin{array}{l}\text { O18... } \\
\text { His } 99 / \mathrm{H}\end{array}$ & 2.077 & $\begin{array}{l}\text { 018... } \\
\text { Arg136/HH11 }\end{array}$ & 2.016 & $\begin{array}{l}\mathrm{H} 30 \ldots \\
\text { Gly101/O }\end{array}$ & 1.658 \\
\hline H27...Gly77/O & 2.167 & $\begin{array}{l}\text { H28... } \\
\text { Val118/O }\end{array}$ & 1.847 & $\begin{array}{l}\text { O20... } \\
\text { Gly77/H }\end{array}$ & 2.495 & $\begin{array}{l}\text { O4... } \\
\text { Lys } 103 / H D 2\end{array}$ & 3.691 \\
\hline $\begin{array}{l}\text { H26... } \\
\text { Gly } 101 / 0\end{array}$ & 2.056 & $\begin{array}{l}\mathrm{O} 20 \ldots \\
\text { Gly102/H }\end{array}$ & 1.868 & $\begin{array}{l}\text { O20... } \\
\text { Glu50/O }\end{array}$ & 3.073 & $\begin{array}{l}\mathrm{H} 24 \ldots \\
\text { Asp73/OD1 }\end{array}$ & 2.020 \\
\hline $\begin{array}{l}\mathrm{H} 25 \ldots \\
\text { Asp73/OD2 }\end{array}$ & 2.350 & $\begin{array}{l}\mathrm{H} 29 \ldots \\
\text { Gly101/0 }\end{array}$ & 2.220 & $\begin{array}{l}\mathrm{H} 24 \ldots \\
\text { Glu50/HA2 }\end{array}$ & 2.341 & 02...Gly77/H & 2.982 \\
\hline $\begin{array}{l}\text { H27... } \\
\text { Arg136/HH21 }\end{array}$ & 2.145 & $\begin{array}{l}\text { O7... } \\
\text { Asn46/HD21 }\end{array}$ & 2.399 & $\begin{array}{l}\mathrm{H} 23 \ldots \\
\text { Arg136/HH11 }\end{array}$ & 2.162 & $\begin{array}{l}\text { 01.. } \\
\text { Arg76/HE }\end{array}$ & 3.379 \\
\hline M5 & & M6 & & M7 & & M8 & \\
\hline 013...Gly77/H & 1.961 & $\begin{array}{l}\text { O7... } \\
\text { Asn46/HD22 }\end{array}$ & 1.830 & $\begin{array}{l}\text { O21 ... } \\
\text { Asn46/HD21 }\end{array}$ & 2.132 & $\begin{array}{l}\text { O7... } \\
\text { Gly119/H }\end{array}$ & 1.965 \\
\hline H29...Gly77/O & 2.168 & $\begin{array}{l}\text { H43... } \\
\text { Asn46/O }\end{array}$ & 2.062 & $\begin{array}{l}\text { H48... } \\
\text { Ala100/O }\end{array}$ & 2.053 & $\begin{array}{l}\text { O7.... } \\
\text { Asn46/HD22 }\end{array}$ & 1.901 \\
\hline $\begin{array}{l}\text { O19... } \\
\text { Arg136/HH11 }\end{array}$ & 2.215 & $\begin{array}{l}\text { O6... } \\
\text { Lys103/HZ1 }\end{array}$ & 2.091 & $\begin{array}{l}\text { O28... } \\
\text { Phe104/HB2 }\end{array}$ & 1.846 & $\begin{array}{l}\text { O1... } \\
\text { Asn46/HD11 }\end{array}$ & 2.056 \\
\hline 011...Gly75/H & 2.763 & H50...lle94/O & 2.040 & $\begin{array}{l}\text { H51... } \\
\text { Gly117/O }\end{array}$ & 2.295 & $\begin{array}{l}\text { O6... } \\
\text { Lys103/HZ2 }\end{array}$ & 1.675 \\
\hline $\begin{array}{l}\text { O8... } \\
\text { Lys103/HZ1 }\end{array}$ & 3.482 & $\begin{array}{l}\text { O9... } \\
\text { Phe104/HB2 }\end{array}$ & 2.503 & $\begin{array}{l}\text { O18... } \\
\text { Val120/HG21 }\end{array}$ & 2.425 & $\begin{array}{l}\text { O10... } \\
\text { Gly } 117 / H\end{array}$ & 2.168 \\
\hline $\begin{array}{l}\mathrm{H} 26 \ldots \\
\text { Asp73/OD2 }\end{array}$ & 2.701 & $\begin{array}{l}\text { O4... } \\
\text { Lys103/HE2 }\end{array}$ & 1.978 & $\begin{array}{l}\text { O16... } \\
\text { Lys103/HE3 }\end{array}$ & 2.572 & $\begin{array}{l}\text { O8... } \\
\text { Lys103/H }\end{array}$ & 1.834 \\
\hline M9 & & M10 & & & & & \\
\hline O8...Lys 103/H & 1.935 & $\begin{array}{l}\mathrm{H} 40 \ldots \\
\text { Glu42/OE1 }\end{array}$ & 1.734 & & & & \\
\hline $\begin{array}{l}\text { H49... } \\
\text { Glu42/OE1 }\end{array}$ & 1.971 & $\begin{array}{l}\text { H38... } \\
\text { Glu42/OE1 }\end{array}$ & 1.906 & & & & \\
\hline $\begin{array}{l}\text { O9... } \\
\text { Asn46/HD11 }\end{array}$ & 1.863 & $\begin{array}{l}\text { H38... } \\
\text { Val118/H }\end{array}$ & 2.292 & & & & \\
\hline 07...Val120/H & 2.142 & С30...lle94/0 & 2.893 & & & & \\
\hline $\begin{array}{l}\text { H44... } \\
\text { Asp73/OD1 }\end{array}$ & 2.162 & $\begin{array}{l}\text { O8... } \\
\text { His } 99 / C D 2\end{array}$ & 3.219 & & & & \\
\hline $\mathrm{H} 41 \ldots$ & 1.879 & & & & & & \\
\hline
\end{tabular}


Table 2 Different physiochemical descriptors using the energy of the frontier molecular orbitals.

\begin{tabular}{llllllllll} 
Molecule & Etotal & $\mathrm{I}$ & $\mathrm{A}$ & $\Delta \mathrm{E}$ & $\eta$ & $\mathrm{X}$ & $\mu$ & $\omega$ & D (Debye) \\
& $(\mathrm{a} . \mathrm{u})$. & $(\mathrm{ev})$ & $(\mathrm{ev})$ & $(\mathrm{ev})$ & $(\mathrm{ev})$ & $(\mathrm{ev})$ & $(\mathrm{ev})$ & $(\mathrm{ev})$ & \\
\hline M1 & -948.46 & 0.227 & 0.094 & 0.133 & 0.066 & 0.161 & -0.161 & 0.0008 & 4.459 \\
\hline M2 & -948.49 & 0.242 & 0.117 & 0.125 & 0.063 & 0.179 & -0.179 & 0.001 & 1.977 \\
\hline M3 & -1022.11 & 0.245 & 0.121 & 0.123 & 0.062 & 0.183 & -0.183 & 0.001 & 2.289 \\
\hline M4 & -987.55 & 0.226 & 0.091 & 0.135 & 0.068 & 0.159 & -0.159 & 0.0008 & 3.163 \\
\hline M5 & -873.68 & 0.239 & 0.101 & 0.138 & 0.069 & 0.170 & -0.170 & 0.001 & 0.925 \\
\hline M6 & -1555.83 & 0.229 & 0.103 & 0.126 & 0.063 & 0.166 & -0.166 & 0.0009 & 2.214 \\
\hline M7 & -1555.79 & 0.238 & 0.112 & 0.126 & 0.063 & 0.175 & -0.175 & 0.001 & 4.487 \\
\hline M8 & -1555.78 & 0.228 & 0.093 & 0.134 & 0.067 & 0.161 & -0.161 & 0.0008 & 4.564 \\
\hline M9 & -1629.32 & 0.245 & 0.097 & 0.148 & 0.074 & 0.171 & -0.171 & 0.001 & 4.056 \\
\hline M10 & -1481.01 & 0.234 & 0.096 & 0.137 & 0.069 & 0.165 & -0.165 & 0.0009 & 4.222
\end{tabular}

\section{Figures}




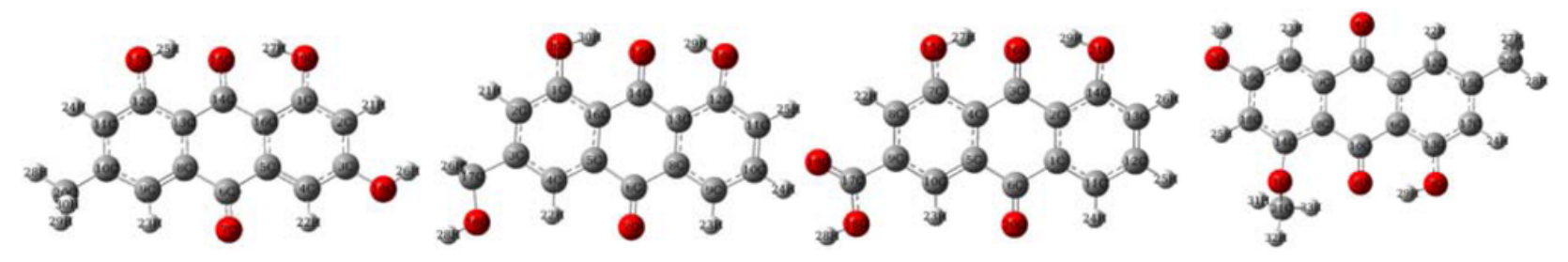

(a)

(b)

(c)

(d)

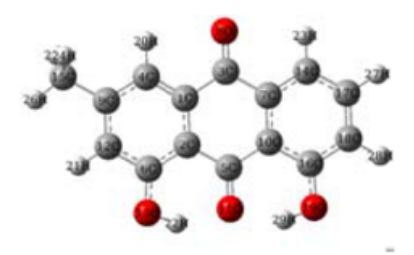

(e)

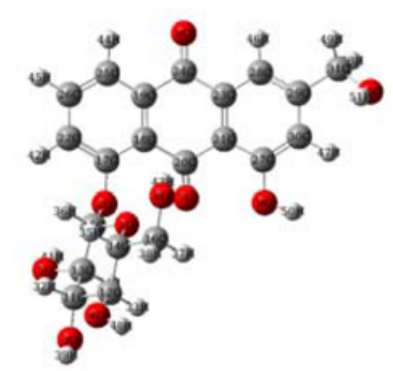

(h)

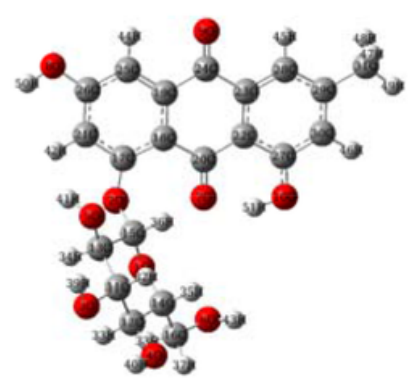

(f)

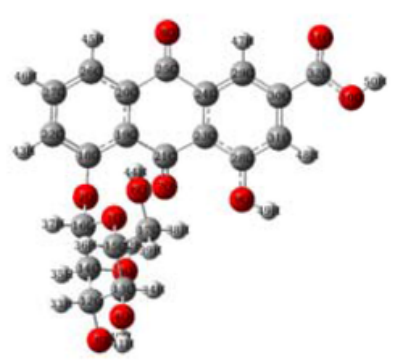

(i)

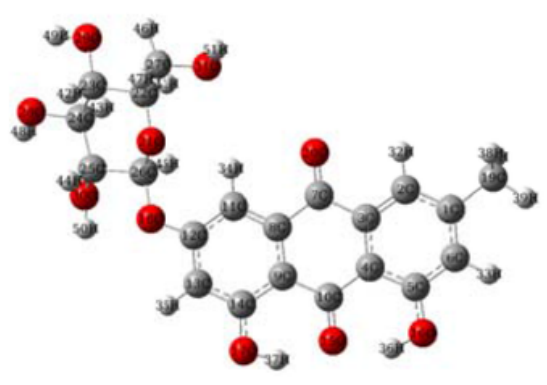

(g)

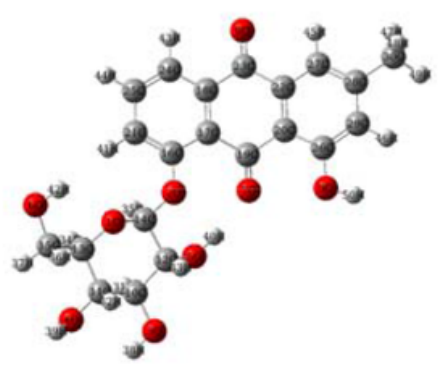

(j)

Fig.1 Schematic diagram of two-dimensional plane structure of (a) Emodin, (b) Aloe_emodin, (c) rhein, (d) emodin 8-methyl ether,

(e) Crysophanol,

(f) Emodin-8-beta-D-glucoside,

(g) Emodin-6-O-

beta-D-glucopyranoside,

(h)

Aloe-emodin-8-O-beta-D-glucopyranoside, (i) Rhein 8-O-beta-D-Glucopyranoside and (j) Chry'sophanol-8-O- glucoside. The number and type of the atoms have been indicated.

\section{Figure 1}

See image above for figure legend 


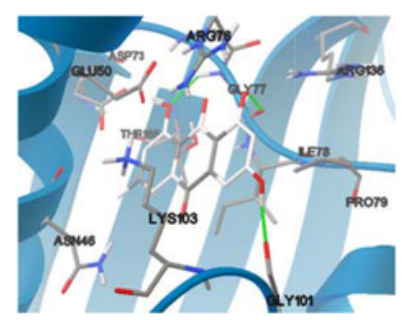

(a)

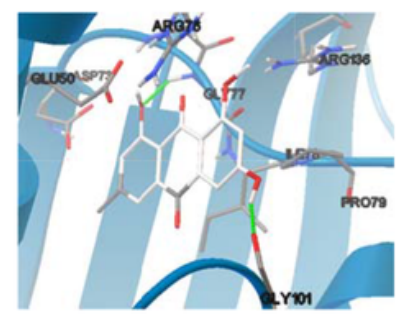

(d)

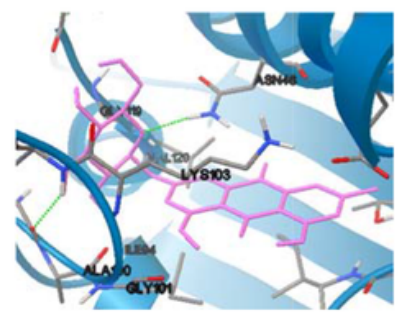

(g)

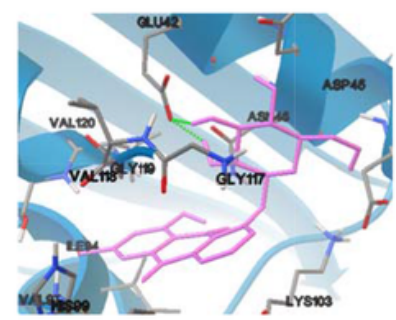

(j)

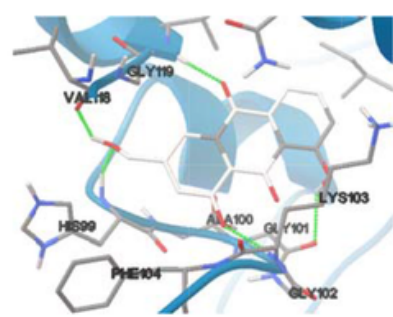

(b)

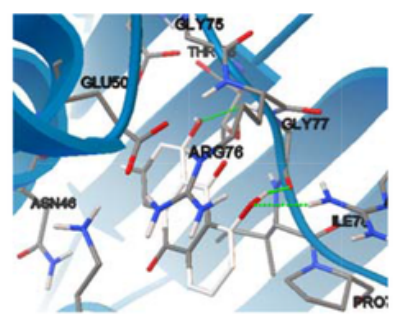

(e)

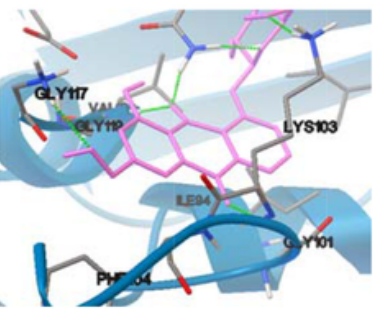

(h)

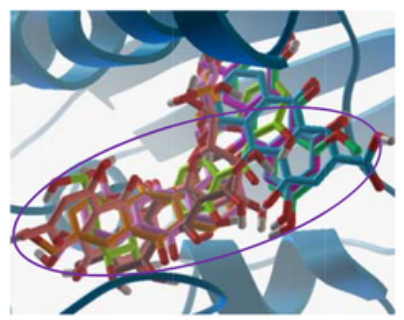

(k)

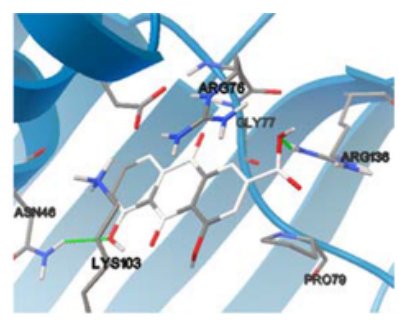

(c)

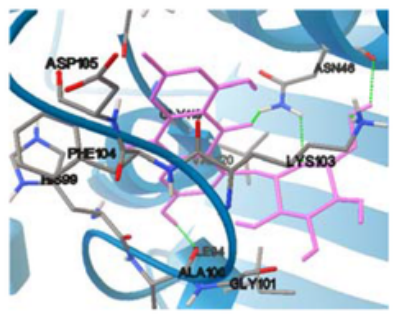

(f)

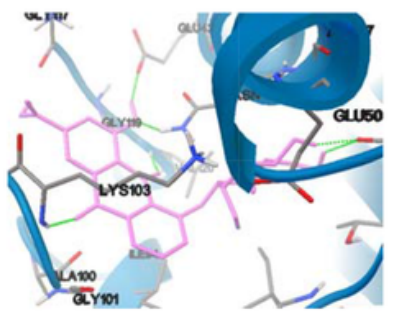

(i)

Fig.2 Intermolecular interactions between the compounds of molecule I-X (a-k) and the DNA gyrase B, respectively. Hydrogen bonds are depicted as green dotted lines, and the compounds M1-M5 and M6-M10 are displayed by gray and pink lines, respectively.

\section{Figure 2}

See image above for figure legend 


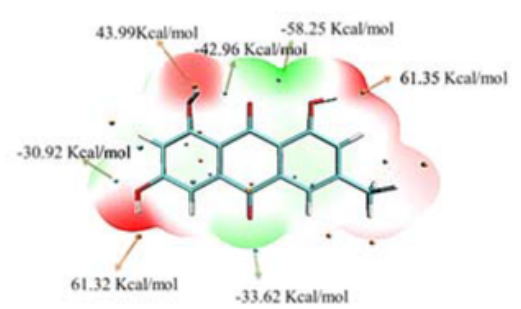

(a)

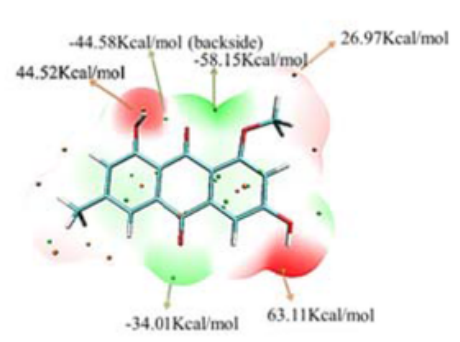

(d)

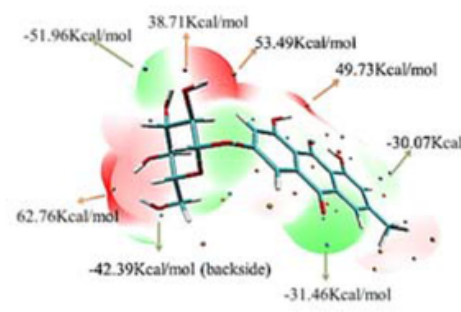

(g)

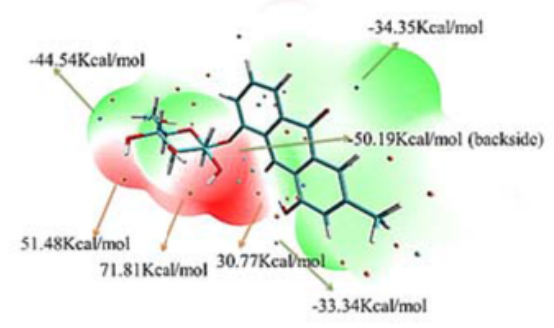

(j)

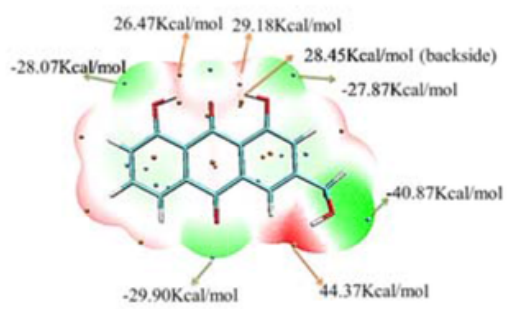

(b)

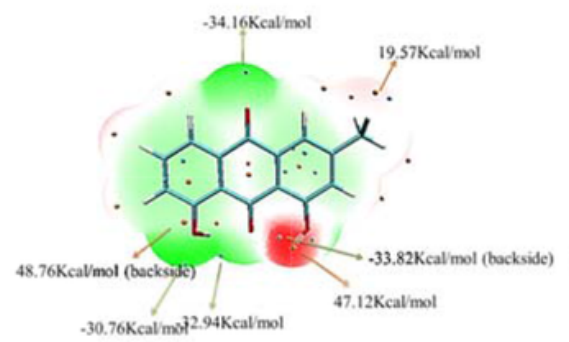

(e)

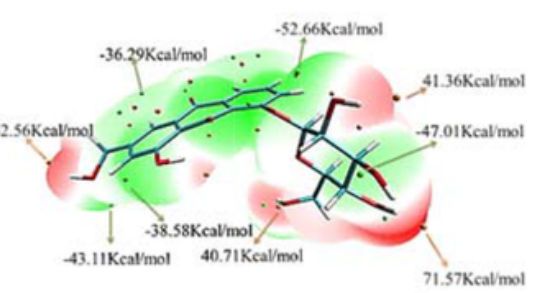

(h)

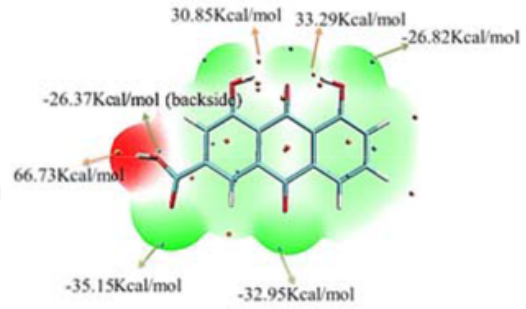

(c)

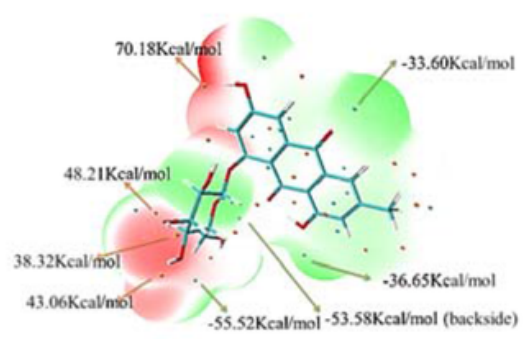

(f)

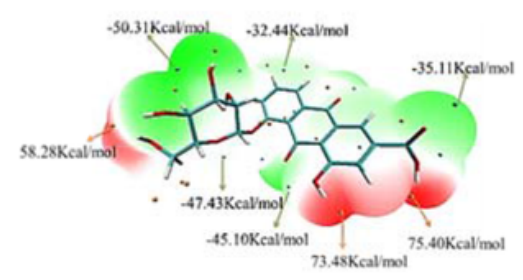

(i)

Fig. 3 Molecular electrostatic potential on vdW surface of molecules I-X (a-j). The unit is in $\mathrm{kcal} / \mathrm{mol}$. Surface local minima and maxima of molecular electrostatic potential are represented as green and red spheres, respectively. The local surface maxima values and the global minimum and maximum are labeled by bold font.

\section{Figure 3}

See image above for figure legend 

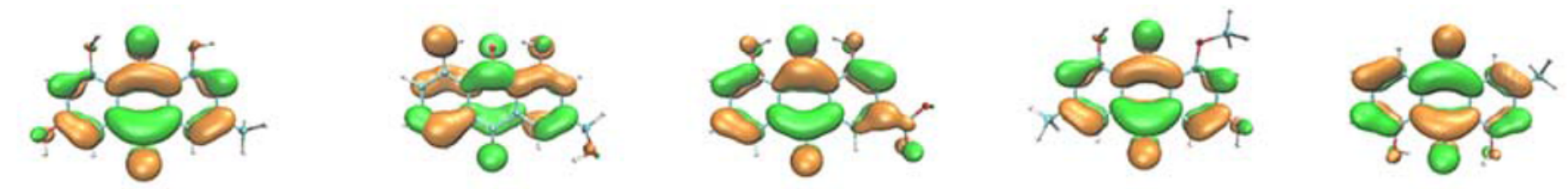

M1 LUMO 71

M2 LUMO_71

M3 LUMO_74

M4 LUMO_75

M5 LUMO_67
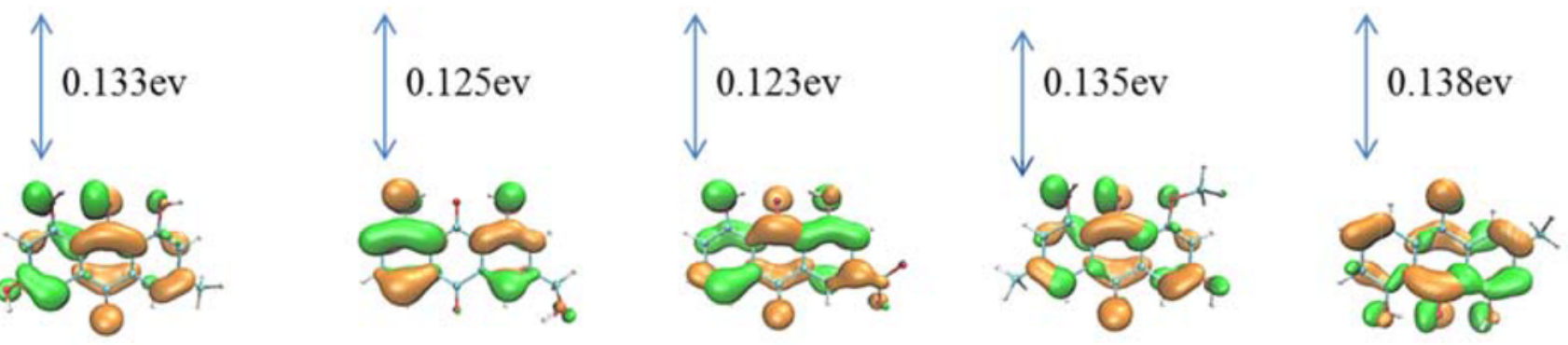

M1 HOMO 70

M2 HOMO 70

M3 HOMO_73

M4 HOMO 74

M5 HOMO_66

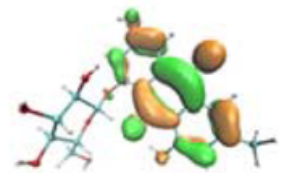

M6 LUMO_114

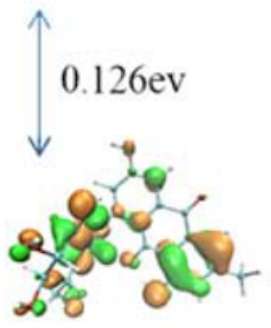

M6 HOMO 113

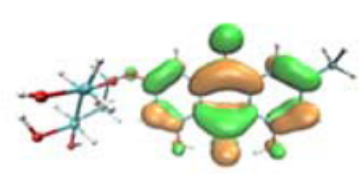

M7 LUMO_114
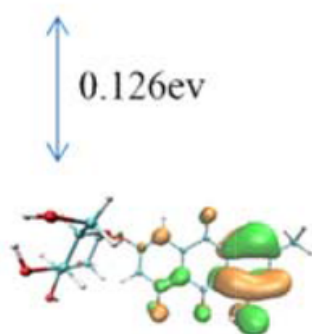

M7 HOMO 113

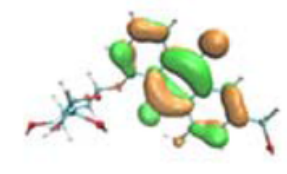

M8 LUMO_114
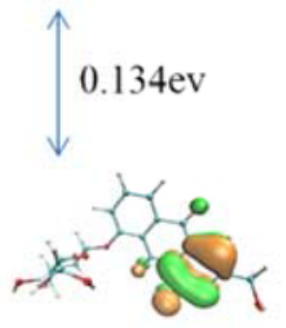

M8 HOMO 113

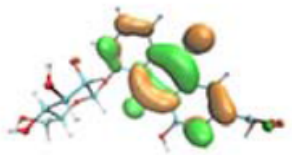

M9 LUMO_117
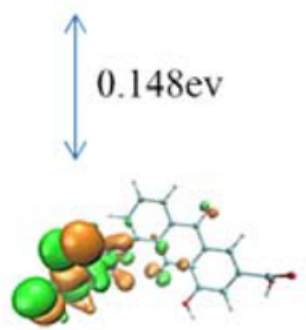

M9 HOMO_116

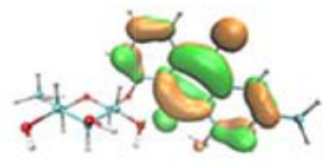

M10 LUMO_110
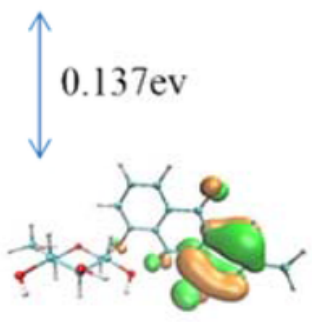

M10 HOMO_109

Fig.4 Frontier molecular orbital density distributions of the molecules at active site.

\section{Figure 4}

See image above for figure legend 


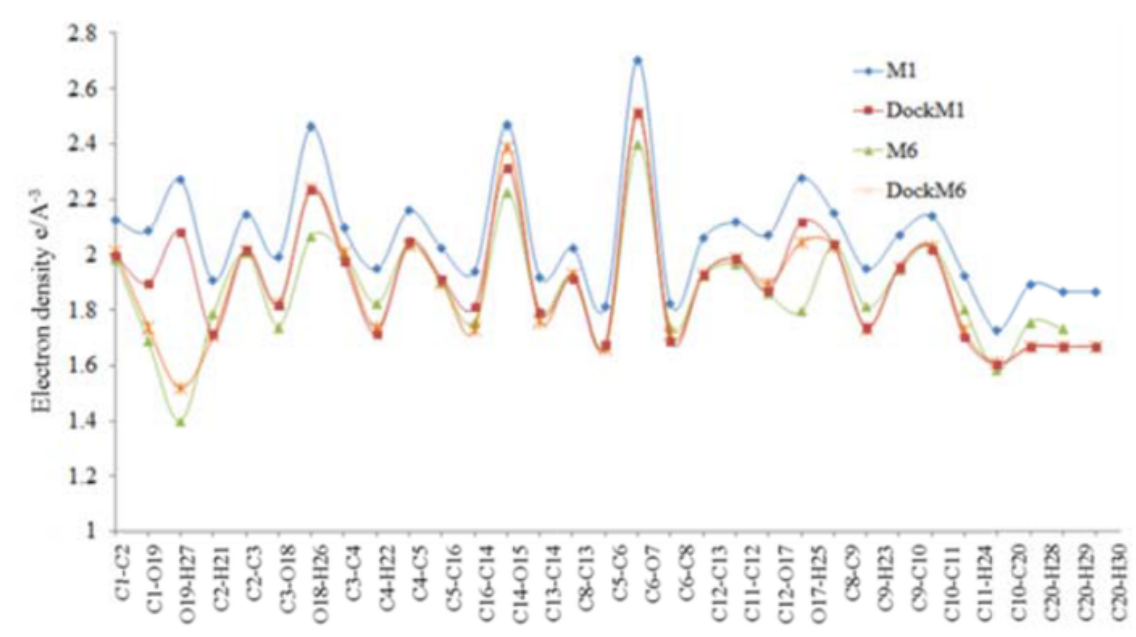

(a)

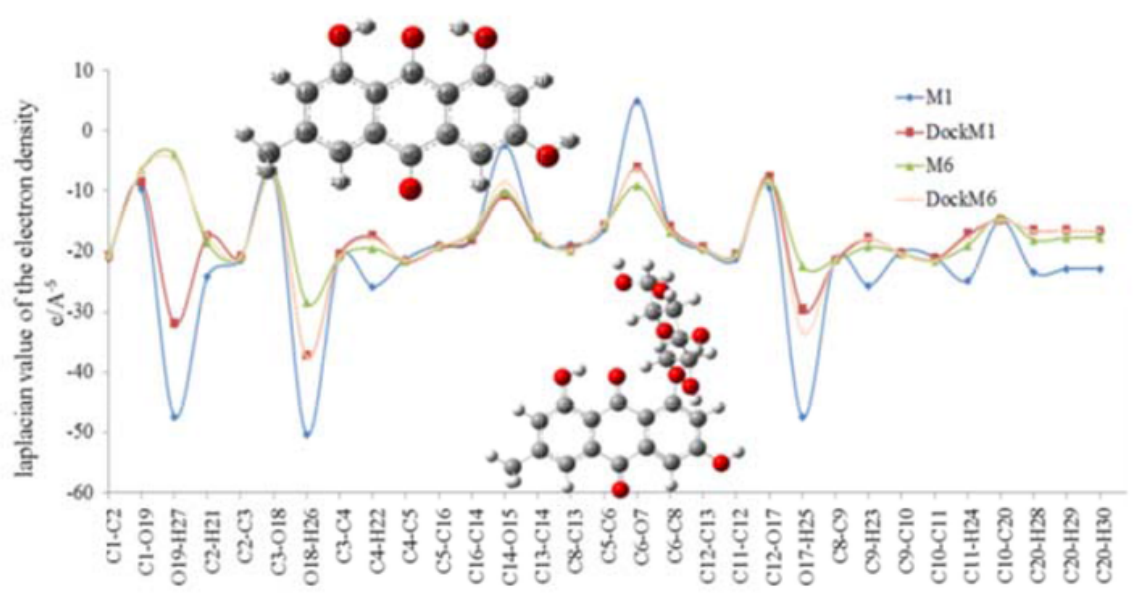

(b)

Fig. 5 Electron densities (a) and Laplacian values of electron densities for M1 and M6 at both status (b).

Figure 5

See image above for figure legend

\section{Supplementary Files}

This is a list of supplementary files associated with this preprint. Click to download.

- Graphicalabstract.png

- Supplementarymaterials.docx 